\title{
Improvement and Analysis of the Winter Thermal Environment of Rural Civilian Dwellings in Northwestern Area of China
}

\author{
Yiyun Zhu ${ }^{1 *}$, Lu Bai ${ }^{1}$, Guochen Sang ${ }^{1}$, Qin Zhao ${ }^{1}$ and Qun Zhang ${ }^{2}$ \\ ${ }^{1}$ Faculty of Civil Engineering and Architecture, Xi'an University of Technology, Shaanxi Xi'an 710048, China \\ ${ }^{2}$ School of Architecture, Xian University of Architecture \& Technology, Shaanxi Xi' an 710055, China \\ *Corresponding author
}

\begin{abstract}
Two typical civilian dwellings, the earth dwelling and the brick and concrete dwelling, in northwestern areas of China were investigated, on-site measurement on winter outdoor meteorological parameters, indoor air temperature and relative humidity were conducted. The paper analyzed space arrangement, construction design, indoor thermal environment and situations of civilian dwellings, the results show that the resources of solar energy in winter in these areas are abundant, however, the indoor thermal environment of the dwelling is not satisfactory. Based on the analysis of indoor and outdoor thermal environment, with the consideration of local natural resources and climate situations, the paper proposes a design plan of energy saving for the traditional dwellings and provides recommendations for the healthy development of local civilian dwellings.
\end{abstract}

Keywords-northwestern areas of China; rural civilian dwelling; indoor thermal environment; passive solar energy heating

\section{INTRODUCTION}

With the rapid development of urbanization in China, the amount of rural dwelling construction becomes larger, the building areas for residence is continuously increasing, and it now has accounted for 51\% [1] of total construction areas of China. However, with the impact of economic conditions, the development of rural dwelling construction is not balanced in Chins. In eastern coastal areas, the dwelling construction develops faster, both quality of house and thermal performance are approaching to the level of urban buildings, but the development in western areas is lagged behind, especially in northwestern areas, the dwelling performance in rural areas has a sharp contradiction with the pursuit of residential environment improvement. The northwestern areas of China refers to three provinces of Shaanxi, Gansu and Qinghai, and two autonomous regions of Ningxia and Xinjiang, as shown in Figure.1, these areas are undeveloped areas in economy, particularly, in most rural areas the economy is not developed yet, the poor economy has restrained the rural dwelling construction, resulted in unfavorable influence on the improvement of livelihood conditions. Taking into account of regional resources, it is an effective way to develop scientifically the rural dwellings with better dwelling performance and the improved residential environmental quality. Among five provinces in northwestern areas of China, Ningxia autonomous region locates in interior areas of the northwestern, it has its own representative climate characters and construction features of civilian dwelling. In Ningxia region, it's cool in summer and cold in winter, winter is long and summer is short, the difference in temperature is large, and it's dry and rainless with plenty of sunshine, the annual average temperature is between 8.2 10 C, the total amount of annual average solar radiation is about $6000 \mathrm{MJ} \cdot \mathrm{m}-2 \cdot \mathrm{a}-1$, the annual sunshine-hour is 3796.1 hours, the building climate region is classified as cold area[2], as shown in Figure.2. and winter indoor thermal conditions of the rural dwelling is the main factor concerned with the quality of indoor thermal environment.

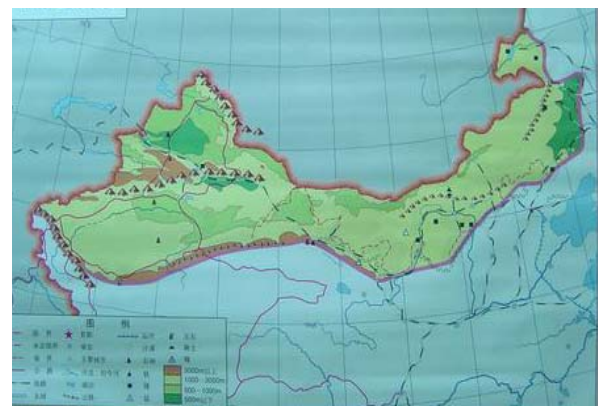

FIGURE I. NORTHWEST OF CHINA

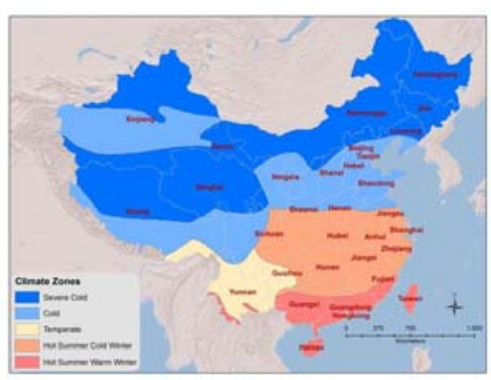

FIGURE II. THE DIVISION OF CHINA'S CLIMATE ZONES.

The traditional rural dwelling in these areas has been built to accommodate the local climate characters in a long process of evolution, however, the dwelling has not adapted to modern production and life style, besides, the form of self-built dwelling in rural areas is only a simple copy of urban building, it lacks of adaptability to the regional climate characters as well as the technology promotion when combining with the advanced building technology, as a result, this has affected the healthy development of rural dwelling. The paper aims to enhance indoor thermal comfort of rural dwelling and decrease 
building energy consumption by inheriting regional features of rural dwelling and combining the regional climate characters in Ningxia region. The research work in this paper includes the investigation and measurement on rural dwelling in Zhongwei city of Ningxia, analyzing indoor thermal environment situations of local rural dwelling. The research is expected to provide a suitable design strategy for the rural dwelling, meanwhile, offer in theory some advice on the building of new countryside.

\section{Measurement Analysis And Present Situation INVESTIGATION ON CIVILIAN DWELLINGS IN RURAL AREAS OF ZHONGWEI REGION}

In January 2015, the research team made an on-site investigation and measurement on typical rural dwellings in Zhongwei city of Ningxia. The investigation includes basic information of rural dwellings, indoor thermal comfort as well as outdoor thermal environment measurement. In the process of investigation, the team gets to know the local dwelling form, indoor thermal environment situation and regional climate features by talking with residents and filling questionnaires.

\section{A. General Situation of Typical Civilian Dwelling}

Through on-site investigation on rural dwellings in Ningxia, it was found that the rural civilian dwelling mainly has two kinds: traditional earth dwelling, brick and concrete dwelling as shown in Figure.3. The dwelling has single floor with a courtyard, it is facing the south and backing the north in layout, the dwellings are designed and constructed to include hall, bedroom, kitchen and utility rooms.

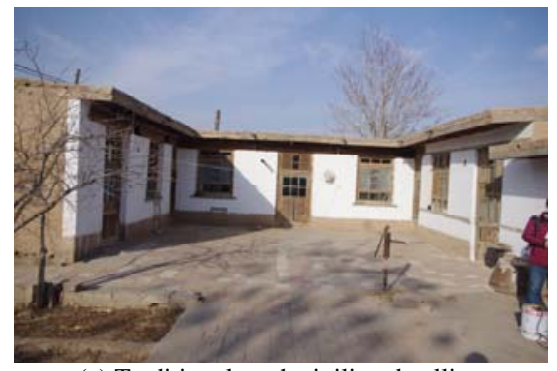

(a) Traditional earth civilian dwelling

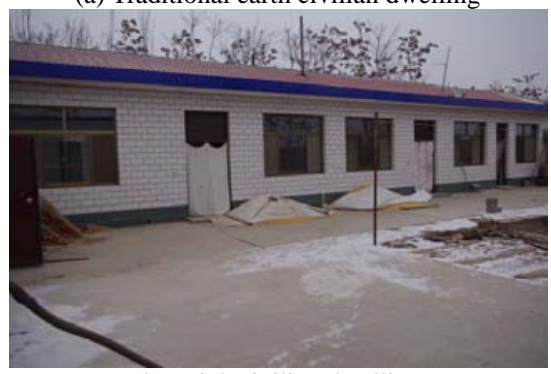

(b) Brick civilian dwelling

FIGURE III. TWO KINDS OF CIVILIAN DWELLINGS IN THE RURAL AREAS IN THE WEST OF NINGXIA PROVINCE

The earth civilian dwelling is built as $U$ shape layout, the hall is in the middle, bedroom, kitchen and utility rooms are on the two sides, exterior walls are built $370 \mathrm{~mm}$ thick toward the south, and $600 \mathrm{~mm}$ thick toward the north and west-east, the roof is built flat, in construction the wooden rafters are placed on the wooden beams, reeds are laid on the rafters, then, yellow mud is spread on the reeds. The doors and windows are made from wood, the sizes of door and window are small.

The brick and concrete civilian dwelling is built as in-line style layout, the hall is in the middle, and bedrooms are on the two sides, the second bedroom is used as storage room when children are not at home, crops are stored inside usually. The exterior walls are built $370 \mathrm{~mm}$ thick, the roof is built in double slope style, rafters are place directly on the load-bearing wall, reeds are laid above, the yellow mud is spread on the reeds, tiles are placed on the mud, windows are made of aluminum alloy with single layer glass, the windows facing the south are bigger. Facing the north, the smaller windows are installed and a little higher in the wall or no windows installed. The doors are plastic steel, a cotton curtain is hung on the door to keep warm inside. Both the earth dwelling and brick and concrete dwelling have ceilings in the halls, heated earthen bed and stove are placed in the hall, the hall also is the main room for activities in winter, it is used as sitting room, kitchen and bedroom together.

The research team learned through the investigation that the heated earthen bed and stove are common heating methods adopted by rural residents in Zhongwei city, as shown in Figure 4.

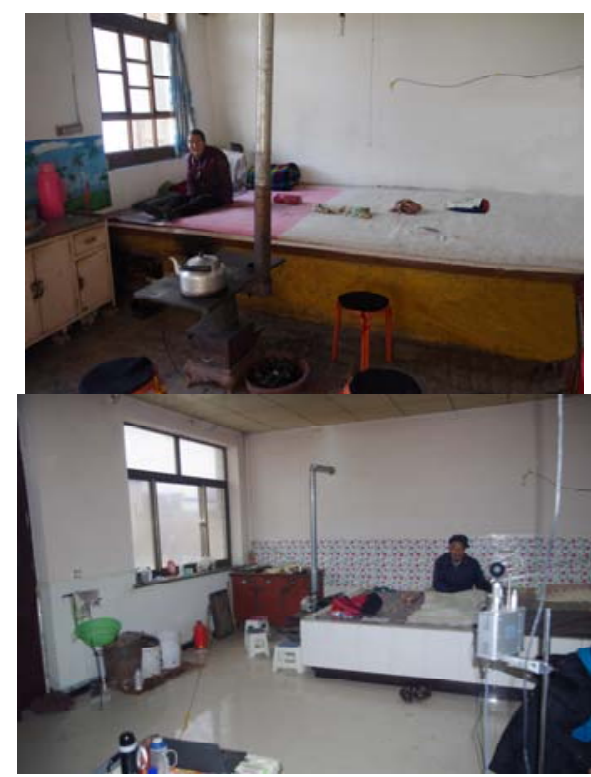

FIGURE IV. CONDITION OF MAIN BEDROOM

\section{B. Measurement and Analysis of Indoor and Outdoor Thermal Environment}

Both typical earth dwelling and brick and concrete dwelling are adopted by the research team for the measurement. The measurement includes the temperature and humidity of indoor and outdoor air, and the intensity of solar radiation. The solar radiation is measured with HD3498938 shading ring, working together with TBQ-DI pyranometer, the measuring range of radiation meter is $0 \sim 2000 \mathrm{~W} / \mathrm{m} 2$, the sensitivity coefficient is $12.470 \mu \mathrm{V} /(\mathrm{W} \cdot \mathrm{m} 2)$, the data-collection interval is $1 \mathrm{~h}$, measuring points are placed in outdoor open areas, there are no shelters around. TR-72U 
Thermohygraphs are adopted to record the temperature and humidity of air, the accuracy of measurement is \pm $0.2^{\circ} \mathrm{C}$,data-collection interval is $1 \mathrm{~h}$, the distribution of indoor measurement points is shown in Figure.5, the outdoor measurement points are placed in shade.

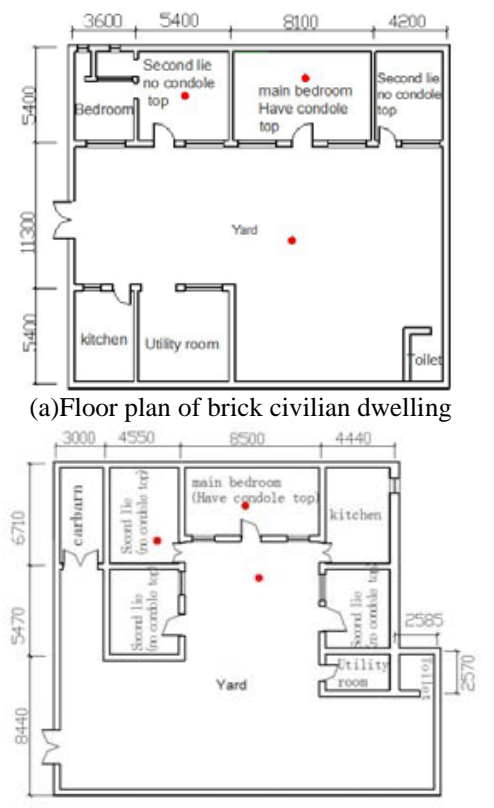

(b)Floor plan of traditional civilian dwelling

FIGURE V. FLOOR PLAN OF AND TEST POINTS FIGURE

\section{1) Solar radiation intensity}

Solar radiation intensity is shown in Figure.6. On the measurement day, the time of sunshine is about 9 hours, the solar radiation intensity on average is $268.1 \mathrm{w} / \mathrm{m}^{2}$, around $13: 30$ Beijing time, the total amount of radiation is $554.7 \mathrm{w} / \mathrm{m}^{2}$, the peak value of scattered radiation appears around 13:30, the radiation intensity is $124.8 \mathrm{w} / \mathrm{m}^{2}$. The intensity of direct sunshine can reach $77.5 \%$ of total intensity of radiation; the intensity of solar radiation is higher. Thus, there is a rich solar energy resource in local areas, according to the research on conditions of passive solar energy thermal utilization[3], the passive design method can be used for local rural civilian dwelling to increase indoor thermal comfort and decrease the heating energy consumption.

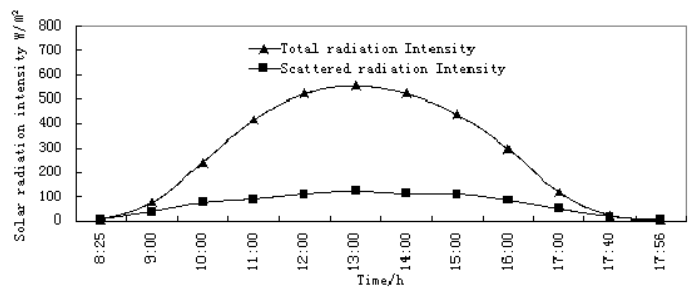

FIGURE VI. OUTDOOR SOLAR RADIATION INTENSITY

\section{2) Indoor and outdoor air temperature}

Hourly records for indoor and outdoor air temperature are shown in Figure.7. During measurement the average outdoor air temperature is $-2.7^{\circ} \mathrm{C}$, the lowest temperature is $-7.2^{\circ} \mathrm{C}$, and the highest temperature is $2.2{ }^{\circ} \mathrm{C}$, daily temperature difference is $9.4{ }^{\circ} \mathrm{C}$. The hall in the civilian dwelling is a main room for activities, one coal stove is used for heating in the daytime, there are no other heating facilities in other rooms. The indoor average temperature in the hall of earth dwelling is $12.08^{\circ} \mathrm{C}$, the peak value of temperature occurs at $16: 00$, the highest temperature is $16.9^{\circ} \mathrm{C}$, the lowest temperature occurs at 7:00 am, the temperature is $7.3^{\circ} \mathrm{C}$, temperature difference is $9.6^{\circ} \mathrm{C}$. the indoor average temperature in the hall of brick and concrete dwelling is $9.48^{\circ} \mathrm{C}$, the peak value of temperature appears at $16: 00$, the highest temperature is $15^{\circ} \mathrm{C}$, the lowest temperature occurs at $6: 00 \mathrm{am}$, the temperature is $6.4^{\circ} \mathrm{C}$, temperature difference is $8.6^{\circ} \mathrm{C}$. The highest temperature in the second bedroom of earth dwelling is $2.5^{\circ} \mathrm{C}$, and the lowest temperature is $-0.1^{\circ} \mathrm{C}$, temperature difference is $2.5^{\circ} \mathrm{C}$, the average temperature is $0.02^{\circ} \mathrm{C}$. The highest temperature in the second bedroom of brick and concrete dwelling is $7.8^{\circ} \mathrm{C}$, the lowest temperature is $1.2^{\circ} \mathrm{C}$, temperature difference is $6.6^{\circ} \mathrm{C}$, the average temperature is $4.02^{\circ} \mathrm{C}$. Under the condition of heating, the temperature in the hall is a little higher than the temperature in the second bedroom. From the second bedroom without heating facilities, it can be found that the earth dwelling has thick wall, which has good thermal storage, and thus, the temperature stability in the second bedroom of earth dwelling is better than the second bedroom in the brick and concrete dwelling. The indoor comfortable temperature range is between $16 \mathrm{C} 24 \mathrm{C}$ [4-5], therefore, the indoor temperature in the dwellings did not meet the demand of comfort.

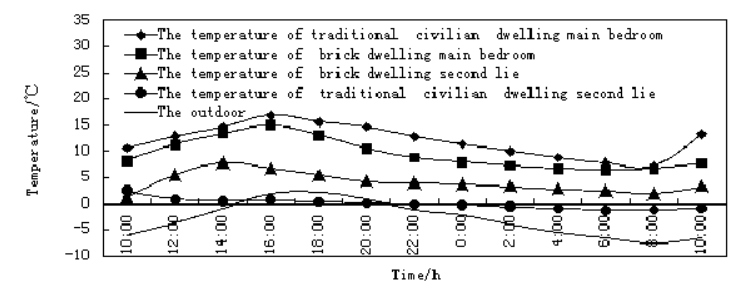

FIGURE VII. TEMPERATURE OF THE OUTDOOR AND INDOOR OF CIVILIAN DWELLING

\section{3) Indoor and outdoor air relative humidity}

The changes of indoor and outdoor air relative humidity are shown in Figure.8, the average value of outdoor air humidity is $42.6 \%$, the minimum value reaches to $24.5 \%$ at $16: 00$, and the maximum value of $51 \%$ occurs at $12: 40$. The average value of indoor relative humidity in the hall of earth dwelling is $35.5 \%$, and the maximum value is $49.4 \%$ at $10: 00$, the lowest value reaches $34.9 \%$ at $16: 00$. The average value of indoor relative humidity in the hall of brick and concrete dwelling is $31.7 \%$, the maximum value is $54 \%$ at $8: 00$, the lowest value reaches $23 \%$ at $16: 40$, and the relative humidity is less than30\% between 8:00 16:00. It can be found from the measurement that the relative humidity of earth dwelling fluctuates less, the humidity of earth dwelling is higher than the humidity of brick and concrete dwelling. This is because the main part of envelope for the earth dwelling is adobe wall, it is a porous medium, and has small resistance in vapor transmission[5], and the vapor may diffuse easily from the side with high partial pressure to another side with low partial pressure, besides the human comfort humidity in the daytime 
in the brick and concrete dwelling has exceeded the lower limit [6-7] , the indoor air is dry.

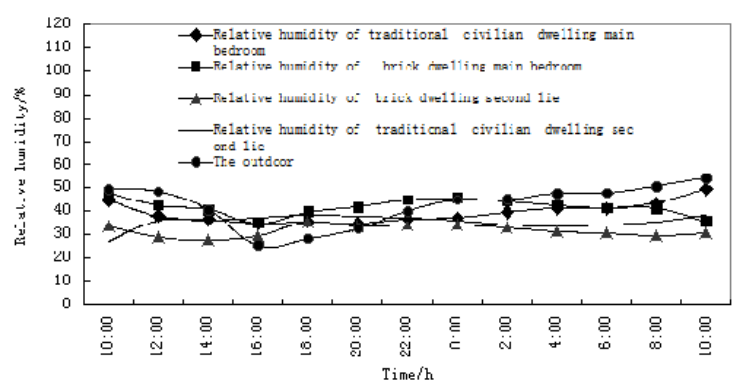

FIGURE VIII. RELATIVE HUMIDITY OF THE OUTDOOR AND INDOOR OF CIVILIAN DWELLING

\section{ANALYSIS OF THERMAL PERFORMANCE ON RURAL DWELLING}

The rural dwellings have the characters to fit the regional climate in the long term of evolution, the local area is rich in solar energy resources, the form of dwellings mainly designed to obtain more solar radiation, for instance, the dwellings usually are built toward the south with its back against the north, the main rooms have bigger windows toward the south, smaller windows are installed toward the north or no windows installed at all, the exterior walls are $370 \mathrm{~mm}$ thick, or the thickness of the walls toward the north is increased (earth dwelling), these measures have created favorite conditions in forming passive sunrooms. However, there are no relevant specifications to guide the construction; the self-built rural dwellings still have many disadvantages, leading to the poor dwelling thermal environment. Through the investigation and measurement made by the research team, these disadvantages are as follows:

\section{A. Space Arrangement and Orientation}

The research team found that the rural dwellings in Zhongwei city have regular layout, all of the dwellings are built toward the south with its back against the north, the main rooms in the dwelling are placed toward the south, and these arrangements are good at obtaining heat from the sun. But the layout of the dwellings is simple; the rooms are single-sided arrangement that makes the coefficient of building size bigger, less practical. The area of hall is a bit larger, the layout is rather simple, and the envelope has more cold emission to human body, moreover, it increases the cold air infiltration throughout the wall in winter as well as the heat transfer of wall, and directly affects the indoor thermal environment. Meanwhile, it's very cold outside in winter, the rooms with heated earthen bed are the main activity places, and the functions are more concentrated, the functional subarea of building is not clear.

\section{B. Size and Type of the Windows}

The windows in the earth dwelling are small, and there are no windows installed toward the north in the dwelling, the type of windows is made from wood with single layer of glass, thus, the indoor temperature in winter is lower, the humidity is high, and in summer it's hot, humid and lacking of ventilation in the rooms. The windows in brick and concrete dwelling are bigger, the material of window changes from wood into aluminum alloy, it can be found from the temperature analysis that the room temperature is increased, mainly due to the increase of heat from the sun and the decrease of heat loss. Nevertheless, wooden windows and doors with single layer or aluminum alloy windows and doors with single layer have poor thermal performance; the air tightness is not good, cold air infiltration is severe.

\section{Construction Mode of Exterior Envelope}

The thick wall of earth dwelling is better for keeping the temperature in rooms, particularly, the northern wall has no solar irradiation, its thickness is increased and heat loss is decreased accordingly. Meanwhile, because earth has good thermal capacity, the room temperature fluctuates less, besides, the ceiling is hung in the main rooms, and it strengthens the heat conservation in the rooms. The wall of brick and concrete dwelling has large coefficient of heat transfer and poor heat storage, leading to a heavy fluctuation of room temperature. The roof of civilian dwelling in Zhongwei City usually is built with the rafters placed on the beams, and then the reeds are laid on the rafters, yellow mud is spread on the reeds and then the tiles are placed, this kind of construction has larger coefficient of heat transfer, leading to more heat losing from the roof.

\section{Heating Method}

Burning coal stove and heated earthen bed are the main heating methods, since the heating consumes high energy, the coal is burned in lower utilization efficiency, it also causes poor indoor sanitary and thermal environment.

\section{CONCLUSIONS}

Through the measurement and analysis of rural civilian dwellings in Ningxia, and on the basis of rural residents' life, construction type as well as original building style, the passive solar energy technology should be fully considered when designing the space arrangement plan, at the same time, new ecological building plan by which new energy saving technology has been integrated into traditional dwellings should be introduced so as to offer some new ideas for the design of civilian dwellings in Ningxia rural areas. The conclusions can be obtained as follows:

(1) The layout of local civilian dwellings is rather simple, functional subarea is not clear and less practical, thermal performance of envelope works is poor, indoor thermal environment is not satisfied. Thus, the method of combining functional subarea with thermal environment subarea, planning the reasonable space arrangement, improving the thermal performance of envelope, these will make indoor thermal environment better.

(2) The local area is rich in solar energy, but the solar energy has not been used effectively, so the passive solar energy heating can be adopted to improve indoor thermal comfort for local civilian dwellings.

(3) Combining the local resources with climate characters, and through improving heat-collection, heat storage and the features of thermal performance of envelope, these can improve the winter indoor thermal situations. 


\section{ACKNOWLEDGEMENT}

This study was financially supported by the NSFC (No.51278419), the Science Technology Project of Shaanxi Education Department (Project No.2013JK0945), Foundation for Innovation Research Groups of NSFC (No.51221865).

\section{CONFLICT OF INTERESTS}

The authors declare that there is no conflict of interests regarding the publication of this article.

\section{REFERENCES}

[1] Jiangyi, Research Report on Annual Report of Chinese Building Energy Saving 2013, Beijing: China Architecture and Building Press 2013.

[2] Sang Jianren, Liu Yulan ,Linli ,Comprehensive Evaluation on Solar Radiation Characters and Potential of Solar Energy Utilization in Ningxia. Journal of Desert Research, Volume 26(2006),issue 01: 122-125.

[3] Karsten Voss ,Solar energy in renovation-results and experience of international demonstration buildings. Energy and Building,Volume 32(2000) issue 3: 291-302.

[4] Tsinghua University Research Center on Building Energy Saving, Research Report on Annual Report of Chinese Building Energy Saving.The first Edition .Beijing: China Architecture and Building Press 2014.

[5] Younoussa Millogo, Mohamed Hajjaji , Raguilnaba Ouedraogo,Microstructure and physical properties of

lime-clayey adobe bricks .Construction and Building Materials, Volume 22(2008) issue 12: 2386-2392.

[6] Tanzia Sharmin, Mustafa Gül, Xinming Li, Veselin Ganev, Ioanis Nikolaidis ,Mohamed Al-Hussein, Monitoring building energy consumption, thermal performance, and indoor air quality in a cold climate region ,Sustainable Cities and Society, Volume 13(October 2014) : 57-68.

[7] Ezra Sohar, Men,microclimate and society: Physiological requirements of the human body for comfortable indoor climate. Energy and Buildings, Volume 4(1982), issue 2: 149-154. 